\title{
Energy, Matter, Life, Mind, Disease, Death and Humanity in the Universe: A Universal Approach
}

\author{
Mario Gosalvez \\ Chief of Experimental Biochemistry, Clinica and Hospital Puerta de Hierro (1970-2010) \\ Madrid and Majadahonda, Comunidad de Madrid, Madrid, Spain \\ Email: dmg.secre@gmail.com
}

Received October 24 ${ }^{\text {th }}, 2013$; revised November $24^{\text {th }}, 2013$; accepted December $2^{\text {nd }}, 2013$

\begin{abstract}
Copyright (C) 2014 Mario Gosalvez. This is an open access article distributed under the Creative Commons Attribution License, which permits unrestricted use, distribution, and reproduction in any medium, provided the original work is properly cited. In accordance of the Creative Commons Attribution License all Copyrights (C) 2014 are reserved for SCIRP and the owner of the intellectual property Mario Gosalvez. All Copyright @ 2014 are guarded by law and by SCIRP as a guardian.
\end{abstract}

A concise summary of my thinking on some important main concepts is provided becoming now to my mind from inner self reflections, and memories. The influences of several figures of the last century in biology, medicine, higher physics, higher mathematics, first philosophy and wide center politics whom I personally treated were of capital importance as well the nurture from the past great sages.

Keywords: Humanity; Universe; Mind; Life; Disease; Death; Matter; Energy

\section{Introduction}

I feel that the time has arrived already, after almost 70 years of observation of Earth, to present the summary of my thinking, on those great concepts mentioned in the title of this essay, to interested readers with different university preparations. My writing will try to be clear and simple. But the readers, please, should understand that I will try to deal with these great concepts with as much profundity as possible. Also I will look for obliged transparency and the maximal respect to all kinds of past, present or future ways of different consideration.

The order of the exposition is elected to facilitate the didactic development of my opinion, experimental and theoretical knowledge, at present. Some books published in the past eleven decades will be mentioned in the bibliography, really only to make the readers remember some names of the investigators of these matters among which I am the less known. The rational dialectical process is a way needed by humanity in its march towards the truth, for decades, centuries or thousands of years, when dealing with important matters. To find near to completely grasp in every aspect of knowledge, I think that it will be first necessary to understand the contradictory nature of the reality and overcome thus inertias produced by perceptions, emotions, reasons, and previous influences from family, relatives and cultural accruals.

Let me say finally, as an end to these phrases of introduction, that a more ample vision of the essential propositions on these concepts, possibly could emanate in the reader's mind at the end of this ride through my adventure of ideas. Above all, if my main purpose with this concise offering would be reached, the beginning of the search for first seeds for an initial scientific consensus on our Universe. An integrative approach for education will be tried.

\section{Mind}

Mind can be personal or collective. There is mind in different persons, families as well as larger groups of people have global mind up to the entire world. Mind receives in many cultures frequently the denomination as spirit. Both words are used many times in the same sense. We can say for example, in the mind of Americans or in the American spirit, to have a gun gives a sense of security and liberty, giving done the initial traditions of the country. In many languages a word for mind do not exist, like in French, or is borrowed lately strait forward from English.

Let me then, please, pour out of my heart slowly enough, a first intent of a small definition joining my main comprehensions of this dual concept. I will apply it to the human persons although my proposals arise mostly from observations of life's reactions to death or disease. Whether it were in persons, animals, vegetable, the living cells or even the sub-cellular organelles of many kinds in many places:

The thinking, conducing to actions of a person alone or many persons reunited by any type of links, including the time of development together for whatever period, shares always a common base not due to its individual or collective rational abilities summed up. There would possibly be a more transcendental component, which could be fully activated whenever as necessary, emanating from the spirit pertaining to the individual or the collective. Whatever will be respectively, its importance and apparent hierarchy in the issue considered. That surge could act at every moment with implicit or explicit manners. Some of my more important older mentors called it "The Left Hand of God”.

\section{Life}

Similarly, I will attempt for a short definition of Life:

Either, from the single isolated most simple living cell to the more complex society of different humanities in many millions of associated planets, general purposes and suitable mechani- 
sms to approach the finality would exist. I call that notion the “Concatenation Creator, Creation, Creature”. It will maintain a null difference between infinite affirmations and negations, the net result being probably always to gain, above all, in Infinite Benevolence, Love and Power.

The aim of Life at Large will be to evolve, constantly, towards the higher diversity and perfection in every specie, aspect and society, adapting its progress as necessary to any ambient changes. The mechanisms will be the trial and error procedures based in chance directed, by control conceptual centers interrelated among each other, from the simplest to the more complex levels. These components will be capable of memory and decision in a progressive ladder of growing complexity to the utmost simplicity of the perfect beings. When arriving to the humanities, of every kind, with the appearing of symbolic language, the possibility of personal conscience of the spirit, in oneself and in all the other respects could arise and growth or be inculcated and stay along the person's or collective's duration.

\section{Disease}

The regression towards destruction, of any living organism or inert systems in its infinite combinations, would mean the aim to destruction corresponding exactly to the urge for creation, in presentation of the essence of reality in appearance. Every disease could have also therapeutic effect in other illness, including cancer as I recently proposed. This general concept will define a mirror image of the destructive role that can have any new creation on previous order, knowledge and justice, for example. The exquisite net balance between regressive and progressive impetus, would require a very careful and constant spirit's attention with infinitesimal focusing and join integration throughout the whole. Truly aiming collectives progress together, in permanent search of a universal harmony between all parties.

In Spanish, and probably in many other languages in different forms, exist a short way to name this phenomena, deeply anchored in our hearts "there is no bad that for good not arrives nor there is not good enduring one hundred years"

\section{Humanity}

One of the main finalities, of each universe of our infinite universal series, in its cycles between appearing and disappearing from duration extension, would be approach to the development of living beings with as much as possible infinite capacities. This achievement could have already neared somewhat in the Terminal Human Entities of the older planets in our universe. These Terminal Human Entities, furthermore of face, hands, foots and lungs, would have wings and gills to mimic the rides for the earth, air and water of the more evolved animals creatures.

In two words, my impression is that it could be obtained the mixture of eagles and dolphins with humans. In hundreds of millions years of terminal science it could be arrived to mixed perfect creatures for these rides. They will have about sixty six chromosomes probably. Of course, their possible intense spiritualization would give these marvelous final humans a corporal luminous halo. In which a transitory annulment would occur eventually endowing them the capacity of instantaneous transportation, to any place and time, only by willing it if they had concourse of The Spirit considered as a universal whole.
Possibly those more perfect persons that will be hermaphrodites capable of fecundating themselves, would summarize in its genesis from fecundation to birth, the totality of the more perfect species existing previously to their consecution by the Concatenation Creator Creation Creature. Probably this achievement took more than nine thousand millions years. They will die probably by a final dilution in an immense ball of light entering definitively in Nothingness.

All universe's humanities together, from hominoids of differrent types to Terminal Human Entities of several kinds, passing by various consecutions of human chimeras, will represent the final diversity perfect gradation of humanity. Humans however would represent a very minuscule fraction of the biomass in the Universe, in which the major component by far will be the unicellular beings.

\section{Death}

Every living being has to die. Any creation sooner or later has to be destructed. Of course the time span of existence is very different from mountains or oceans, that may last many millions years, to those tiny lives that only last minutes or the atomic molecules or subatomic particles, that only are seen by complex instruments. These final components only last for few milliseconds or nanoseconds respectively.

Civilizations in the beginnings of science only last for some thousand years. The United Earth would be approaching at the end of this century an advance state of civilization. Probably in about one hundred fifty years with the possible reencounter with our Godfathers planets in our galaxy and galaxies no too far away. That exterior new impetus would delay human death almost one hundred years and bring numerous other advantages in all respects. The more crucial thing in this possible event is to be duly prepared in all aspects to enter into the Human Interplanetary Society as a new planet with full rights. The final bilateral decision only will be completed after some hundred years, by a really complete universal referendum of all persons with the use of reason inhabiting the Earth.

\section{Universe}

The universe would have around a thirty per cent of its galaxies with habitable zones, like it has one the small spiral galaxy in which Earth turns around its center each 22,000 years. For each galactic habitable zone, from $1 \%$ to $8 \%$ approximately of their best planets would have developed life, but only a $10 \%$, as a mean, of those living worlds would have diverse humanity forms. The more perfect humanities, in the sense of approaching better the infinite capacities would be probably only a $0.01 \%$. Among these planets would be our principal Godfathers Planets in terminal civilization. Their top leadership would be mainly composed by the Human Final Entities of the utmost complete perfection presently existing in our universe.

The Earth would have had perhaps the visits and the genes accruals of some relatively advanced human terminal forms, those most similar to us, at certain periods of the last 750,000 years. The last relatively long visit would have finished probably about 12,000 years. Having now each human being, of all our races, in a very minor part of its genetic arrangement differrent advanced gene associations from these exterior visitors.

The only, really an anecdotic proportion, few thousand singular persons that did improve our successive civilizations in all respect in the last 9000 years, would represent fortunate crosses 
summed during many generations. These persons would represent a small higher proportion of those better genes entered much before from the exterior space to their remote ancestors.

In periods of about 600 years, each around 3 to 6000 years, those singular persons births would be relatively more numerous and strong, thus giving the necessary impetus to the Earth for the change of each era. One of these periods would have started for our humanity probably 300 years ago and will end perhaps in another 300 years with the formal incorporation of our planet in the Interplanetary Human Society of The Galaxy and The Universe.

\section{Energy}

Our universe will represent mostly empty space alternating with empty time almost fully concreted its conceptual delimitation by energy relationships. That participation in what I call the fundamental (Ergy) will be arranged in two spirals of many millions of galaxies, one going to exterior periphery, the expanding universal limit and the other to the interior original and final concentration, the beginning and end of each successive universe of our series.

The atoms of matter, speaking at the other extreme of size of our energy scale, will have the same construction but considering subatomic particles instead galaxies and its cumuli. Total matter in our universe represents a small fraction of the total energy. Total life only amounts to an anecdotic minuscule universal component.

It would be thus necessary to take and develop the abandoned Theory of Ether to arrive to understand properly the delimitation of extension and duration, in the ether field, as a vibratory alternative, perceptible only by an infinitesimal duration to the senses and instruments. Human advanced forms will have the possibility to contemplate the reality in three different forms, apparent, essential or both. The first way would be also call "Animal Perception", the second "Divine Apprehension” and the third "Angelic Manifestation". In this last situation advanced humans would be able to trespass the solids at will with the body of with the hands.

\section{Matter}

Perhaps the more important considerations trying to define essentially matter are three: first, from the scientific point of view its almost total emptiness; second, the great inertial consideration going from the more complex living beings to the more simple inert structures; third, the astonishing capabilities of matter, in conjunction with energy as cements in the progression towards infinite diversity and perfection with full respect to the laws of chance.

In an attempt to convey a bypass to the more ambitious readers of this first abstract of the reunion of my deepest knowledge, I will finally say that if the charnel between concepts and numbers and duration extension would be the ether, the key event between inert matter and life will be metabolic energy. To arrive and pass to the corner from humans to angels, however, "Spiritual Densification” will be need.

\section{REFERENCES}

Dobbs, B. J. T. (1975). The foundations of Newton's alchemy. Manuel, F. E. (1974). The religion of Isaac Newton.

Castillejo, D. (1981). The expanding force in Newton's cosmos.

Burgers, J. M. (1965). Experience and conceptual activity. A philosophical essay based upon the writings of A. N. Whitehead.

Hawkins, S. (2001). The universe in a nutshell.

Harris, E. H. (1987). Formal transcendental \& dialectical thinking: Logic and reality.

Crik, T. (1981). Life itself. Its origin and nature.

Penrose, R. (2004). The road to reality. A complete guide to the laws of the universe.

James, W. (1902). The varieties of religious experience. A study in human nature.

Dawkings, R. (2006). The god delusion.

Ruse, M. D., \& Design (2003). Does evolution have a purpose?

Gosalvez y Gosalvez, M. (1981). Towards a cosmological concept of life.

Tudge, C. (2000). The variety of life. A survey and celebration of all the creatures that have ever lived.

Gosálvez y Gosálvez, M. (1982). The zipper mechanism.

Hoyle, F. (1983). The intelligent universe. A new view of creation and evolution.

Gosalvez y Gosalvez, M. (2007). Theos. Reunion of panentheos, solideo, ateos (1987-1989) done privately also en 2007. Public edition of this mystic poetry in Spanish expected in 2014 in English and French. Previously was disseminated restrictively privately.

Grant, E. (1981). Much Ado about nothing. Theories of space and vacuum from the middle ages to the scientific revolution.

Cantor, G. N., \& Hodge, M. J. S. (1981). Conceptions of ether. Studies in the history of ether theories 1740-1900.

Kauffman, S. (1995). At home in the universe. The search for laws of complexity.

Gosalvez, M. (2014). A new emerging capacity of human mind. impulses, intuitions and interior visions from inner self. Presently in consideration by SAGE Science Publishers.

Gosalvez, M. (2014). The limits of science. An optimistic speculation. 